\title{
Determinantes do rendimento acadêmico dos discentes dos cursos de agronomia e zootecnia em uma instituição de ensino superior privada
}

\author{
Determinants of academic performance of students of agronomy and zootechnics courses at a \\ private higher education institution \\ Determinantes del desempeño académico de estudiantes de cursos de agronomía y zootecnia en una \\ institución privada de educación superior
}

\author{
Francis Barbosa Ferreira \\ ORCID: https://orcid.org/0000-0002-2353-6049 \\ Faculdades Associadas de Uberaba, Brasil \\ E-mail: francisbferreira@gmail.com \\ Wilson de Sousa Benjamin \\ ORCID: https://orcid.org/0000-0002-1560-6641 \\ Universidade de Uberaba, Brasil \\ E-mail:wilson.benjamin@uniube.br \\ Michelli Maldonado \\ ORCID: https://orcid.org/0000-0002-8822-5508 \\ Universidade Federal do Triângulo Mineiro, Brasil \\ E-mail: michelli.oliveira@uftm.edu.br \\ Sandra Cristina Dantas \\ ORCID: https://orcid.org/0000-0003-4775-040X \\ Universidade Federal do Triângulo Mineiro, Brasil \\ E-mail: sandra.dantas@uftm.edu.br
}

\begin{abstract}
Resumo
Neste trabalho, realizou-se uma análise dos principais resultados obtidos em uma pesquisa sobre o perfil socioeconômico dos estudantes dos cursos de Agronomia e Zootecnia da FAZU - Faculdades Associadas de Uberaba, frente ao desempenho na disciplina de Química que é ministrada no primeiro período dos cursos. O método investigativo baseou-se na aplicação de um questionário aos acadêmicos no início do semestre letivo. A partir dos resultados, foi possível identificar que os cursos são formados por um público jovem, com idade média de 17 a 20 anos, com predominância do sexo masculino, solteiros, oriundos em sua maioria de Uberaba e com renda familiar entre 1 e 6 salários mínimos. O índice de aprovação destes alunos na disciplina de Química Inorgânica e Analítica da FAZU foi de $58,46 \%$. Metade dos alunos que responderam ao questionário trabalham regularmente. A maioria é formada por alunos oriundos de escola pública, recém terminado o ensino médio, considerando o aprendizado prévio, em química, fraco. Dormem em média 8 horas por dia, e estudam apenas dias antes da prova. Levando em consideração os alunos dos cursos diurno e noturno, a maior parte $(60 \%)$ são dos cursos noturnos. A partir de alguns dados analisados na pesquisa é possível perceber que os alunos do noturno, mesmo com algumas adversidades como maior média de idade, a maioria oriundo de escola pública e com menor renda familiar, a média de aprovação para a disciplina de Química Inorgânica e Analítica da FAZU é maior.
\end{abstract}

Palavras-chave: Ensino; Ensino de química; Perfil sócio-econômico; Rendimento acadêmico.

\begin{abstract}
In this work, an analysis of the main results obtained in a research on the socioeconomic profile of students in the Agronomy and Zootechnics courses at FAZU - Faculdades Associadas de Uberaba was performed, in view of the performance in the Chemistry discipline that is taught in the first period of the courses. The investigative method was based on the application of a questionnaire to academics at the beginning of the academic semester. From the results, it was possible to identify that the courses are formed by a young audience, with an average age of 17 to 20 years old, predominantly male, single, mostly from Uberaba and with family income between 1 and 6 salaries minimums. The approval rate of these students in the discipline of Inorganic and Analytical Chemistry at FAZU was $58.46 \%$. Half of the students who answered the questionnaire work regularly. The majority is made up of students from a public school, having just finished high school, considering previous learning, in chemistry, weak. They sleep an average of 8 hours a day, and study only days before the test. Taking into account students from day and night courses, most $(60 \%)$ are from evening courses. From some data analyzed in the research, it is possible to notice that night students,
\end{abstract}


even with some adversities such as higher average age, the majority coming from public schools and with lower family income, the average approval for the discipline of Inorganic Chemistry and FAZU's analytics is greater.

Keywords: Teaching; Chemistry teaching; Socio-economic profile; Academic performance.

\section{Resumen}

En este trabajo se realizó un análisis de los principales resultados obtenidos en una investigación sobre el perfil socioeconómico de los estudiantes de los cursos de Agronomía y Zootecnia de la FAZU - Faculdades Associadas de Uberaba, en vista del desempeño en la disciplina Química que se imparte en el primer período de los cursos. El método de investigación se basó en la aplicación de un cuestionario a los académicos al inicio del semestre académico. De los resultados se pudo identificar que los cursos están conformados por un público joven, con una edad promedio de 17 a 20 años, predominantemente hombres, solteros, mayoritariamente de Uberaba y con ingresos familiares entre 1 y 6 sueldos. mínimos. La tasa de aprobación de estos estudiantes en la disciplina de Química Inorgánica y Analítica en FAZU fue 58.46\%. La mitad de los estudiantes que respondieron al cuestionario trabajan regularmente. La mayoría está compuesta por estudiantes de una escuela pública, que acaban de terminar el bachillerato, considerando el aprendizaje previo, en química, débil. Duermen un promedio de 8 horas al día y estudian solo días antes de la prueba. Teniendo en cuenta los estudiantes de cursos diurnos y nocturnos, la mayoría (60\%) son de cursos nocturnos. A partir de algunos datos analizados en la investigación, es posible notar que los estudiantes nocturnos, aún con algunas adversidades como edad promedio mayor, la mayoría proveniente de escuelas públicas y con menores ingresos familiares, el promedio de aprobación para la disciplina de Química Inorgánica y La analítica de FAZU es mayor.

Palabras clave: Ensenãnza; Enseñanza de la química; Perfil socioeconómico; Desempeño académico.

\section{Introdução}

Nos últimos anos vem ocorrendo no Brasil um processo de intensificação ou massificação do ensino. Este processo ganhou força devido às transformações sociais, culturais e políticas ocorridas, neste período, as quais influenciam diretamente o processo educacional (Tomazetti \& Schlickmann, 2016). O número de cursos de graduação presenciais passou de 3923, em 1985, para 24827 em 2009, um crescimento de mais de 500\%. O total de concluintes passou de 226.423 alunos em 1980 para 826.928 em 2009 (INEP, 2011). A valorização por parte das empresas por profissionais mais qualificados, com maior grau de escolaridade impulsionou as políticas públicas no sentido de ampliação do ensino superior no país (Martins \& Rocha-deOliveira, 2017).

As mudanças sociais ocorridas neste período também foram bastante intensas, e dentre elas podemos destacar as mudanças nas formas de comunicação e nas formas de obtenção da informação. Estas mudanças acarretam novas mudanças nas formas de produção, comercialização e, consequentemente, a oferta no mercado de trabalho. Estas novas exigências são refletidas nas Instituições de Ensino Superior (IES), fazendo com que estas atendam a necessidade de uma formação mais sintonizada com a nova configuração do mercado de trabalho (Colossi et al., 2001).

Dentro deste contexto, as IES estruturam suas diretrizes no processo de ensino-aprendizagem dos discentes, tendo este processo como propósito fundamental. Neste contexto, o conhecimento dos fatores que influenciam o processo de ensinoaprendizagem é de fundamental importância, visto que a partir deste conhecimento é possível definir políticas educacionais e governamentais, visando garantir que este processo tenha sucesso em todos os seus aspectos (Cunha et al., 2010). Uma das formas que as IESs e, também, o estado utiliza para avaliar a eficiência deste processo é o aproveitamento acadêmico na forma de avaliações dentro da própria instituição e o ENADE (Exame Nacional de Desempenho), por exemplo. Porém, o aproveitamento acadêmico está diretamente ligado ao rendimento acadêmico, um tema ainda carente de pesquisas em várias áreas do conhecimento, mas que vem despertando o interesse de vários pesquisadores no sentido de se identificar as causas do desempenho insatisfatório dos discentes (Medeiros Filho et al., 2019; Rocha et al., 2018; Cunha et al., 2010).

Para Macedo et al. (2003) a avaliação de desempenho deve ser utilizada pelas IESs, docentes ou gestores de curso como uma ferramenta de gestão para quantificar o processo ensino-aprendizagem e transformar estes dados em planejamento buscando a qualidade no ensino. Ainda, para estes autores, a credibilidade de uma IES é diretamente influenciada diretamente pela avaliação de desempenho, a qual afeta a imagem desta IES. 
Nota-se que existe várias formas de se avaliar o desempenho dos discentes, como pela definição por notas (valor numérico) obtidos através de avaliações por provas e trabalhos, de forma mais direta. Este tipo de critério avaliativo, por considerar o resultado final e não o processo de ensino-aprendizagem, além de estar sujeito a utilização de artifícios por parte dos alunos para maximizar o valor e não refletir o desempenho real do aluno em determinada disciplina, poderia não ser o ideal, porém, estes são casos pontuais e diluídos em se tratando de uma mostra extensa (Araújo et al., 2013).

Existem vários fatores que podem influenciar o rendimento acadêmico do discente. Dentre eles estão: sexo, idade, formação básica em instituição pública ou privada, se trabalha ou se dedica exclusivamente ao curso, dentre outros (Ferreira, 2009). Estes fatores, associados ou não, podem ser responsáveis pelo fato de que quase metade dos estudantes não conseguem concluir o curso no tempo previsto ou mesmo não continuar no curso superior.

Jahara et al. (2016) alerta que um dos grandes desafios para as IES está na permanência dos estudantes, de maneira que os ingressantes consigam dar continuidade aos estudos, além de atender cada vez mais estudantes que concluíram o Ensino Médio e não ingressaram em cursos de graduação devido à falta de oportunidade.

Outro aspecto apontado por Marques \& Silva (2017) e que pode influenciar no desempenho dos estudantes é o, que ele denomina, trabalhador-aluno. O trabalhador-aluno é um fenômeno social jovem e tem sua expansão a partir da democratização do acesso ao ensino superior. Este aluno acaba tendo que se deslocar do local de trabalho direto para o local de estudo, gerando atrasos acadêmicos, cansaço e exaustão.

É necessário conhecer os fatores determinantes do desempenho acadêmico, visto que a qualidade do ensino passou a chamar mais atenção com o crescimento acelerado de novos cursos de graduação no país. Portanto, o objetivo deste trabalho foi identificar se o desempenho acadêmico dos discentes do $1^{\circ}$ dos cursos de Agronomia e Zootecnia da Faculdades Associadas de Uberaba (FAZU), mensurado pelas notas finais na disciplina, é influenciado pelas variáveis: idade, sexo, frequência às aulas, cidade de residência, se trabalha, advindos de escola pública ou privada e horas noturnas de sono.

\section{Metodologia}

O estudo foi realizado em uma faculdade privada, a Faculdades Associadas de Uberaba (FAZU), localizada no município de Uberaba - MG. Trata-se de um estudo descritivo quanti-qualitativo, cujo objetivo é descrever e obter um perfil estatístico das percepções dos entrevistados sobre o tema a ser analisado, além de identificar quais variáveis podem influenciar o desempenho acadêmico do discente. Pereira (2018) ressalta que uma pesquisa descritiva estuda as relações entre duas ou mais variáveis de um dado fenômeno sem manipulá-las. É feita a constatação de sua manifestação a posteriori. Para Souza \& Kerbauy (2017) as abordagens qualitativas e quantitativas são necessárias e complementares em tais circunstâncias. É uma abordagem que possibilita mais elementos para atender os anseios desse tipo de pesquisa.

A pesquisa classifica-se também como um estudo de caso, tendo como objetivo de estudo os estudantes ingressantes, $1^{\circ}$ e $2^{\circ}$ períodos, dos cursos de Zootecnia e Agronomia tanto do diurno quanto noturno da FAZU, matriculados na disciplina de Química. Para Soares Pereira et al. (2018) um estudo de caso é uma metodologia de estudo de fenômenos individuais ou, processos sociais. Eles complementam que um caso tem que ter alguma particularidade que o diferencie. $\mathrm{O}$ caso tem que ser descrito e analisado do modo mais detalhado e completo possível.

O levantamento de dados se deu junto ao sistema on-line interno da FAZU e, também, por meio de questionário semiestruturado, constituído de perguntas do tipo abertas, que permitem uma livre resposta do informante, e fechadas, com respostas pré-estabelecidas.

A utilização de questionários é um instrumento importante na coleta de dados. De acordo com Soares Pereira et al. (2018) este instrumento tem como vantagens a possibilidade de alcançar um grande número de participantes e desta forma garantir o anonimato das respostas e sem a influência de opiniões de quem está fazendo a entrevista. 
O questionário foi construído com objetivo de obter informações sobre o perfil dos ingressantes dos cursos de Zootecnia e Agronomia, em 2019. Os principais dados foram: Dados pessoais, Atividade Remunerada, Horas de Sono, Local de Residência. Todos os alunos foram convidados a participar da pesquisa de forma totalmente voluntária.

Participaram 130 estudantes dos $1^{\circ}$ e $2^{\circ}$ períodos, dos cursos de Zootecnia e Agronomia tanto do diurno quanto noturno da FAZU, matriculados na disciplina de Química, que constituíram uma amostra de conveniência.

Após a coleta dos dados, as respostas foram analisadas com base na estatística descritiva, por meio de porcentagens usando o software R.

\section{Resultados e Discussão}

Da população de alunos matriculados na disciplina de Química, da turma do diurno e da turma do noturno, 130 responderam ao questionário. A amostra é composta em maioria por homens (80\%), pessoas da raça branca (63,8\%), com idade entre 17 e 19 anos (64,6\%), que exercem atividade renumerada (50,7\%), solteiros (89,2\%) e sem filhos (91,5\%). Os resultados podem ser observados da na Tabela 1 considerando a porcentagem global (\%) e o intervalo de confiança de $95 \%$ (IC (95\%)) de cada variável analisada.

Dos alunos que responderam a pesquisa, $40 \%$ são da turma do curso diurno e $60 \%$ da turma do curso noturno. Com os índices globais apresentados na Tabela 1, nota-se que os alunos nos cursos de Agronomia e Zootecnia são na sua grande maioria do sexo masculino, o que também é corroborado por estudos realizados em outras instituições, por exemplo no estudo de Artuzo et al. (2012) para o curso de Engenharia Agronômica da Universidade Federal de Santa Maria, e o estudo de Oliveira et al. (2020) para o mesmo curso mas em uma universidade do Tocantins.

A maioria dos alunos tem idade entre 17 e 19 anos. Os alunos com idade superior a 20 anos possuem maior representação no período noturno, como se pode ver na Figura 1.

Figura 1: Idade dos discentes em relação ao curso (noturno x diurno).

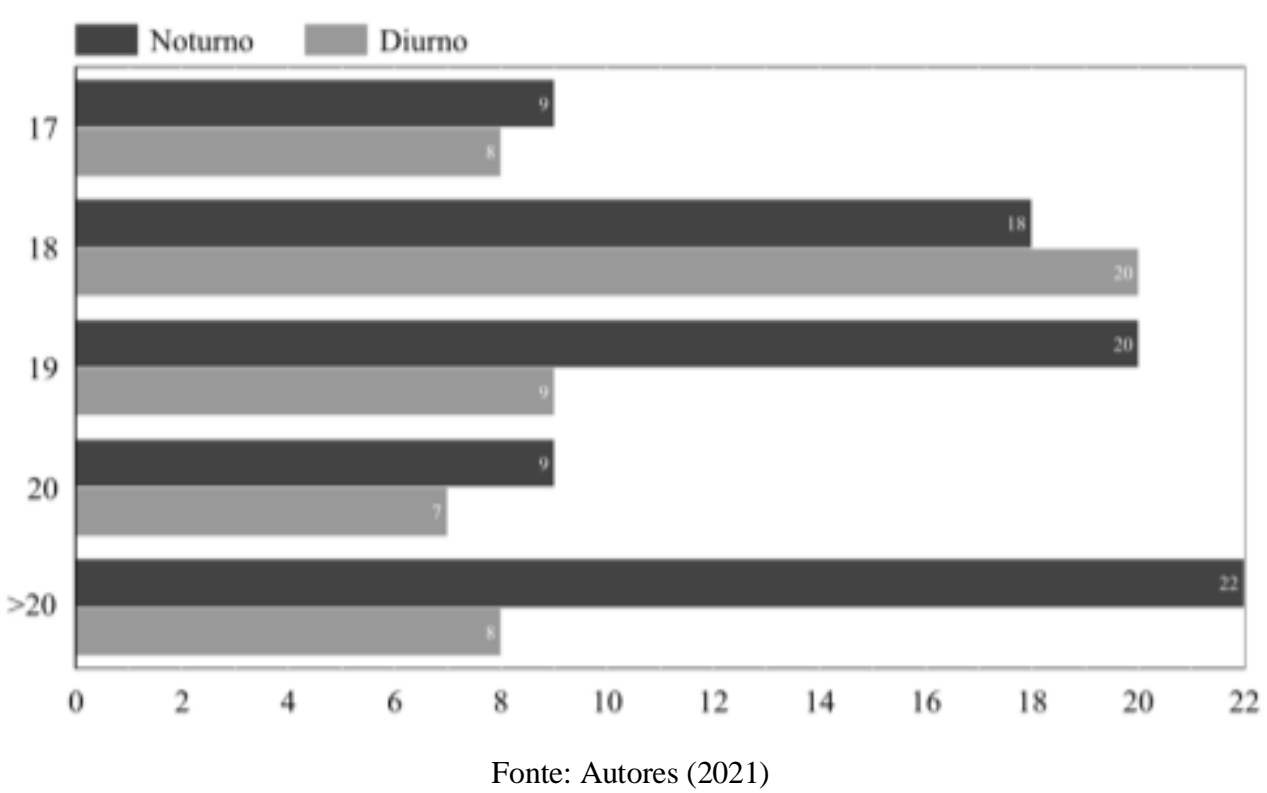

Como apresentado na Figura 1, a maioria dos discentes com mais de 20 anos, 73,4\% são do curso noturno. Dos 130 entrevistados, apenas nove tem idade superior a 30 anos, representando uma parcela de aproximadamente $7 \%$ do todo. Dentre esses, $100 \%$ exercem atividade remunerada, apenas um é do curso diurno e $78 \%$ são casados. 
Há uma predominância de alunos declarados de cor branca e parda, sendo 63,85\% e 29,23\%, respectivamente, perfazendo um total de $93,08 \%$ dos alunos entrevistados. A raça sempre se mostrou um marcador importante para a inserção no ensino superior, percebe-se que pretos, pardos e indígenas aumentaram sua participação representando $34,62 \%$ dos alunos.

Tabela 1: Dados sociodemográficos dos discentes dos cursos de agronomia e zootecnia entrevistados no ano de 2019.

\begin{tabular}{|c|c|c|c|}
\hline \multicolumn{4}{|l|}{ Variável Analisada } \\
\hline & & Global (\%) & IC $(95 \%)$ \\
\hline \multirow{2}{*}{ Sexo } & Feminino & 20,00 & $13,12 \%-26,88 \%$ \\
\hline & Masculino & 80,00 & $73,12 \%-86,88 \%$ \\
\hline \multirow{5}{*}{ Idade } & 17 anos & 13,08 & $7,28 \%-18,88 \%$ \\
\hline & 18 anos & 29,23 & $21,41 \%-37,05 \%$ \\
\hline & 19 anos & 22,31 & $15,15 \%-29,47 \%$ \\
\hline & 20 anos & 12,31 & $6,66 \%-17,96 \%$ \\
\hline & $>20$ anos & 23,08 & $15,84 \%-30,32 \%$ \\
\hline \multirow{5}{*}{ Cor } & Branco & 63,85 & $55,59 \%-72,11 \%$ \\
\hline & Pardo & 29,23 & $21,41 \%-37,05 \%$ \\
\hline & Preto & 3,08 & $0,11 \%-06,05 \%$ \\
\hline & Amarelo & 1,54 & $0,00 \%-03,66 \%$ \\
\hline & Indígena & 2,31 & $0,00 \%-04,89 \%$ \\
\hline \multirow{3}{*}{ Estado civil } & solteiro & 89,92 & $84,74 \%-95,10 \%$ \\
\hline & casado & 8,53 & $3,73 \%-13,33 \%$ \\
\hline & separado & 1,55 & $0,00 \%-03,67 \%$ \\
\hline \multirow{4}{*}{ Filhos } & nenhum & 91,54 & $86,76 \%-96,32 \%$ \\
\hline & $\mathrm{Um}$ & 6,15 & $2,02 \%-10,28 \%$ \\
\hline & Dois & 1,54 & $0,00 \%-03,66 \%$ \\
\hline & Três & 0,77 & $0,00 \%-02,27 \%$ \\
\hline \multirow{6}{*}{ Renda familiar } & 1 a 3 salários & 30,65 & $22,72 \%-38,58 \%$ \\
\hline & 3 a 6 salários & 21,77 & $14,68 \%-28,86 \%$ \\
\hline & 6 a 9 salários & 14,52 & $8,46 \% .-20,58 \%$ \\
\hline & 9 a 12 salários & 15,32 & $9,13 \%-21,51 \%$ \\
\hline & 12 a 15 salários & 5,65 & $1,68 \%-09,62 \%$ \\
\hline & > 15 salários & 12,10 & $6,49 \%$. - $17,71 \%$ \\
\hline
\end{tabular}

Fonte: Autores (2021)

Aproximadamente $90 \%$ dos alunos declararam ser solteiros e não possuírem filhos. A renda familiar destes alunos é variada, tendo representatividade em todas as faixas de renda apresentadas. A maioria $(30,65 \%)$ declarou uma renda familiar de até 3 salários mínimos. A segunda maior faixa de renda declarada foi de 3 a 6 salários mínimos, com 21,77\% dos entrevistados. Na faixa de 6 a 9 e de 9 a 12 salários mínimos ficaram com cerca de 15\% dos entrevistados, cada uma 5,65\% dos entrevistados declararam uma renda de 12 a 15 salários. Acima de 15 salários mínimos, aproximadamente $12 \%$ dos entrevistados. 
Diversos fatores podem influenciar na disponibilidade para o estudo, durante a pesquisa informações de local de residência, se exercem atividade remunerada, horas disponíveis de sono e quais formas adotam para se preparem para as avaliações foram coletadas para tentar identificar quais fatores são predominantes, a Tabela 2 apresenta os resultados considerando a porcentagem global (\%) e o intervalo de confiança de 95\% (IC (95\%)) de cada variável analisada.

É importante destacar que a FAZU se situa na cidade de Uberaba, considerada uma cidade Polo da região do Triângulo Mineiro de Minas Gerais. Dos estudantes entrevistados, 32,31\% relataram viajar todos os dias entre a cidade de sua residência e a faculdade, dos quais, $96,2 \%$ são alunos do curso noturno e exercem atividade remunerada.

Tabela 2: Fatores de disponibilidade de estudo dos discentes dos cursos de agronomia e zootecnia entrevistados no ano de 2019.

\begin{tabular}{clrr}
\hline Variável Analisada & & & \\
\hline \multirow{2}{*}{ Residência } & & Global $(\%)$ & IC (95\%) \\
& Uberaba & 57,69 & $49,20 \%-66,18 \%$ \\
& Vai e volta (todos os dias) & 32,31 & $24,27 \%-40,35 \%$ \\
& Vai e volta (final de semana) & 10,00 & $4,84 \%-15,16 \%$ \\
\hline \multirow{2}{*}{ Trabalha } & Sim & 50,77 & $42,18 \%-59,36 \%$ \\
& Não & 49,23 & $40,64 \%-57,82 \%$ \\
\hline \multirow{2}{*}{ Horas de sono } & até 4 horas & 5,43 & $1,53 \%-09,33 \%$ \\
& de 4 a 5 horas & 10,08 & $4,90 \%-15,26 \%$ \\
& de 5 a 6 horas & 20,16 & $13,26 \%-27,06 \%$ \\
& de 6 a 7 horas & 16,28 & $9,93 \%-22,63 \%$ \\
& de 7 a 8 horas & 10,85 & $5,50 \%-16,20 \%$ \\
& 8 horas & 21,71 & $14,62 \%-28,80 \%$ \\
& mais de 8 horas & 15,50 & $9,28 \%-21,72 \%$ \\
\hline \multirow{2}{*}{ Forma de estudo } & diariamente & 11,54 & $6,05 \%-17,03 \%$ \\
& semanalmente & 25,38 & $17,90 \%-32,86 \%$ \\
& dias antes da prova & 48,46 & $39,87 \%-57,05 \%$ \\
& no dia da prova & 9,23 & $4,25 \%-14,21 \%$ \\
& raramente estuda para a prova & 5,38 & $1,50 \%-09,26 \%$ \\
\hline
\end{tabular}

Fonte: Autores (2021)

As análises das respostas sobre o fato de exercer ou não atividade remunerada, mostraram que 50,2\% dos entrevistados trabalham, dos quais, $86,4 \%$ são do período noturno. O teste Qui Quadrado $\left(\chi^{2}=38,82\right.$, df $=1$, p-value < 0,001) mostra que de fato há forte relação associativa entre estas variáveis. O mesmo acontece quando se compara as variáveis atividade remunerada com local de residência. O teste Qui Quadrado $\left(\chi^{2}=12,722\right.$, $\mathrm{df}=2$, p-value $\left.<0,001\right)$ apresenta evidências de associação entre o fato de exercer atividade remunerada e o local de residência.

A maior oferta de cursos, incluindo o ensino superior noturno, facilitou o acesso do trabalhador-aluno ao curso superior nesse horário. Porém muitas vezes esses alunos têm conciliado o trabalho remunerado com os estudos em horários alternativos e finais de semana. 
De acordo com Coelho et al. (2010) o sono é um fenômeno essencial para a sobrevivência, tem como função primordial a restauração corporal e mental, com diversos efeitos fisiológicos, entre eles o processamento de vários tipos de memórias. Os autores também comentam que os indivíduos em fase de profissionalização em nível superior apresentam maior privação de sono com tendência à sonolência excessiva, e como consequência, queda do desempenho escolar. Verificou-se que entre os entrevistados da FAZU, que 51,95\% dormem menos que 7 horas diárias, sendo que o recomendado pela Associação Brasileira do Sono é de 7 a 9 horas diárias.

Na Figura 2 pode-se notar que a maioria dos discentes que declararam dormir menos que 7 horas são os que também declararam que exercem atividade remunerada, 97\%. Pelo teste do Qui Quadrado $\left(\chi^{2}=66,37, \mathrm{df}=6, \mathrm{p}\right.$-value $\left.<0,001\right)$ nota-se a forte relação entre a quantidade de horas de sono e o fato de exercer atividade remunerada. Também é estatisticamente significante quando se relaciona a quantidade de horas de sono com a localização da residência dos entrevistados $\left(\chi^{2}=28,212\right.$, $\mathrm{df}=12, \mathrm{p}$-value $=0,005)$, dos que relataram dormir 7 horas ou mais, 79,4\% moram em Uberaba.

Figura 2: Relação entre a quantidade de horas de sono com a atividade remunerada.

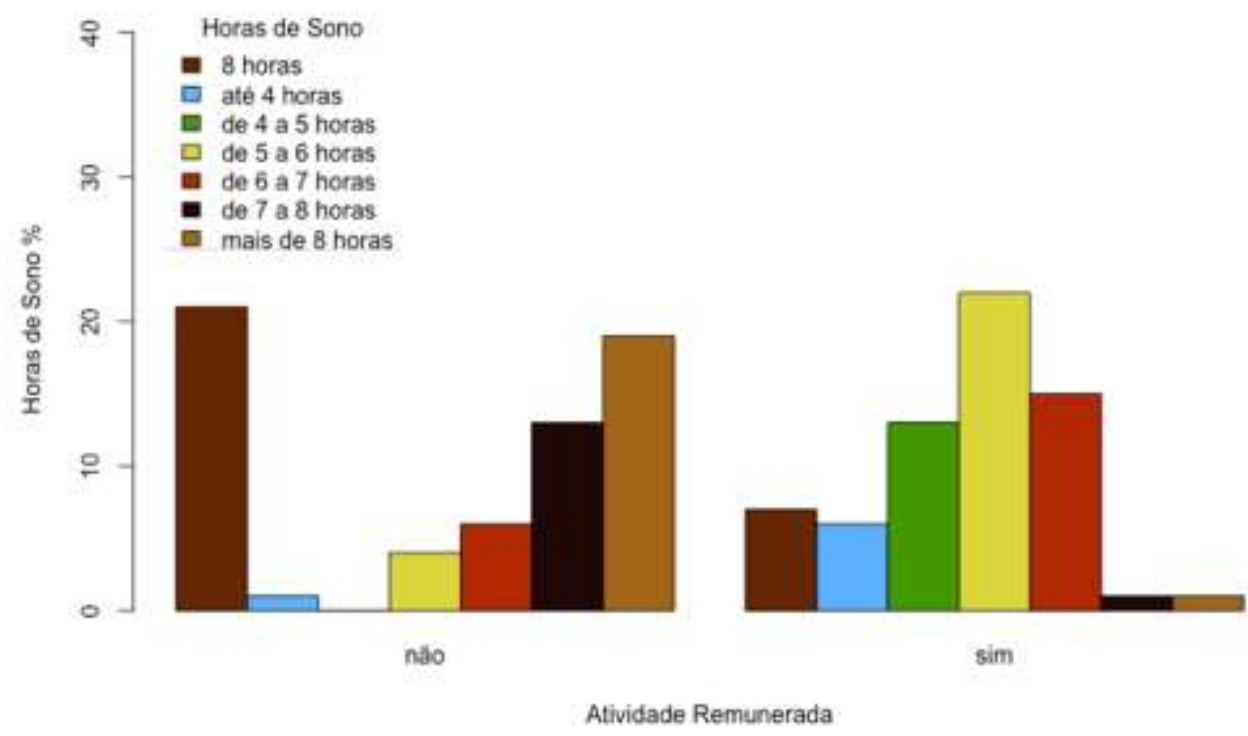

Fonte: Autores (2021)

Com relação à questão que abordada sobre a principal forma de estudo dos entrevistados, $63,07 \%$ desses estudantes relataram que raramente estuda para as provas, ou estuda às vésperas ou até mesmo no dia da prova. Não é estatisticamente significante quando se associa a forma de estudo com o período, noturno ou diurno e muito menos quanto ao sexo.

A Figura 3 apresenta a relação entre a forma de estudo e o fato do discente exercer ou não atividade remunerada. Observe na Figura 3 que os alunos que declararam estudar diariamente, 67\% não trabalham, sendo que os que exercem atividade remunerada disseram estudar aos finais de semana. O teste Qui Quadrado $\left(\chi^{2}=11,65, \mathrm{df}=4\right.$, $\mathrm{p}$-value $\left.=0,02\right)$ também apresenta a forte relação associativa entre essas variáveis. 
Figura 3: Relação entre a forma de estudo com a atividade remunerada.

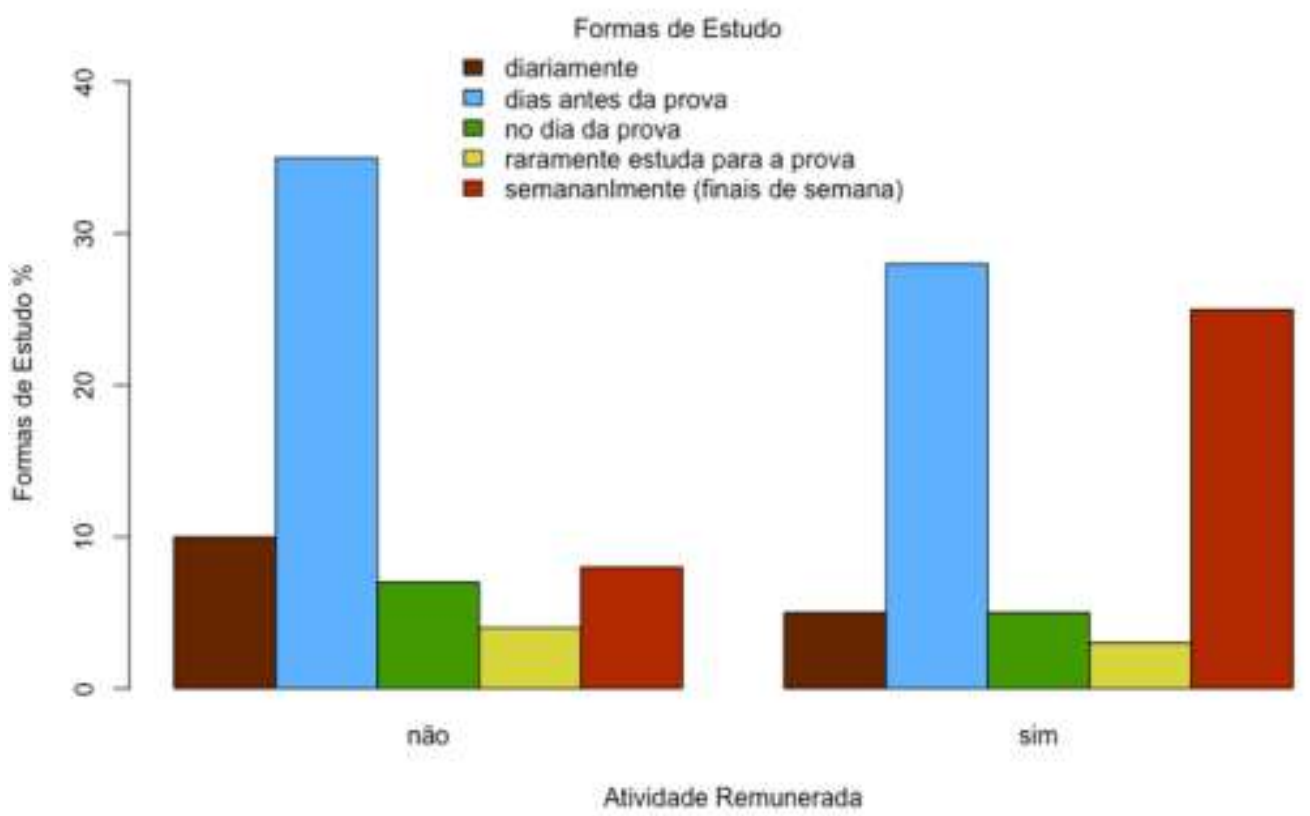

Fonte: Autores (2021)

De acordo com Oliveira et al. (2020) o ensino médio tem papel importante na formação escolar de qualquer estudante e é fundamental para a preparação do indivíduo para o prosseguimento dos estudos por meio da educação superior e para o mercado de trabalho. No que tange ao ensino médio, o estudo mostrou que a maioria dos entrevistados, 59,23\% curso em escola pública. Os resultados gerais desta variável e de outros fatores de estudo prévio dos discentes dos cursos de agronomia e zootecnia entrevistados no ano de 2019, podem ser observados da na Tabela 3 considerando a porcentagem global (\%) e o intervalo de confiança de 95\% (IC (95\%)) de cada variável analisada.

A Figura 4 apresenta o tipo de ensino durante o ensino médio e qual o curso, noturno ou diurno, que o discente se encontra hoje. É evidente que os alunos do período noturno têm a maioria dos que estudaram em escola pública, enquanto o curso diurno, a maioria declarou ter estudado o ensino médio todo em escola particular. Ao nível de 5\% de significância verifica-se a relação associativa entre as variáveis citadas $\left(\chi^{2}=70,44, \mathrm{df}=2\right.$, $\mathrm{p}$-value $\left.<0,001\right)$. Dos que declararam ter estudado todo o ensino médio em escola pública, $88,3 \%$ deles hoje estudam no período noturno, enquanto apenas 9,5\% dos que estudaram todo o ensino médio em escola particular encontram-se no curso noturno.

Outro aspecto ainda relacionado com o conhecimento prévio dos alunos é em relação ao tempo que eles estão longe dos estudos. Dos entrevistados, 45,38\% declararam que concluíram o ensino médio a menos de 6 meses. Aproximadamente 23\% dos alunos entrevistados concluíram o ensino médio entre 1 e 3 anos. Entre 6 meses e 1 ano de conclusão, 15\%. E quase 14\% concluíram o ensino médio a mais de 3 anos, sendo que 8,46\% destes concluíram a mais de 10 anos. Apesar de 35,38\% dos entrevistados considerarem o aprendizado em química prévio como fraco, a maioria, 56,15\% considera mediano ou bom.

A Tabela 4 apresenta o desempenho acadêmico dos discentes entrevistados frente a disciplina de Química. Nota-se que a maioria apresentou um coeficiente satisfatório, classificado como "Aprovado". Enquanto 13,85\% por algum motivo (Abandono, Cancelamento, Trancamento) não finalizaram a disciplina. 
Figura 4: Relação entre o tipo de ensino médio e o curso (noturno x diurno).

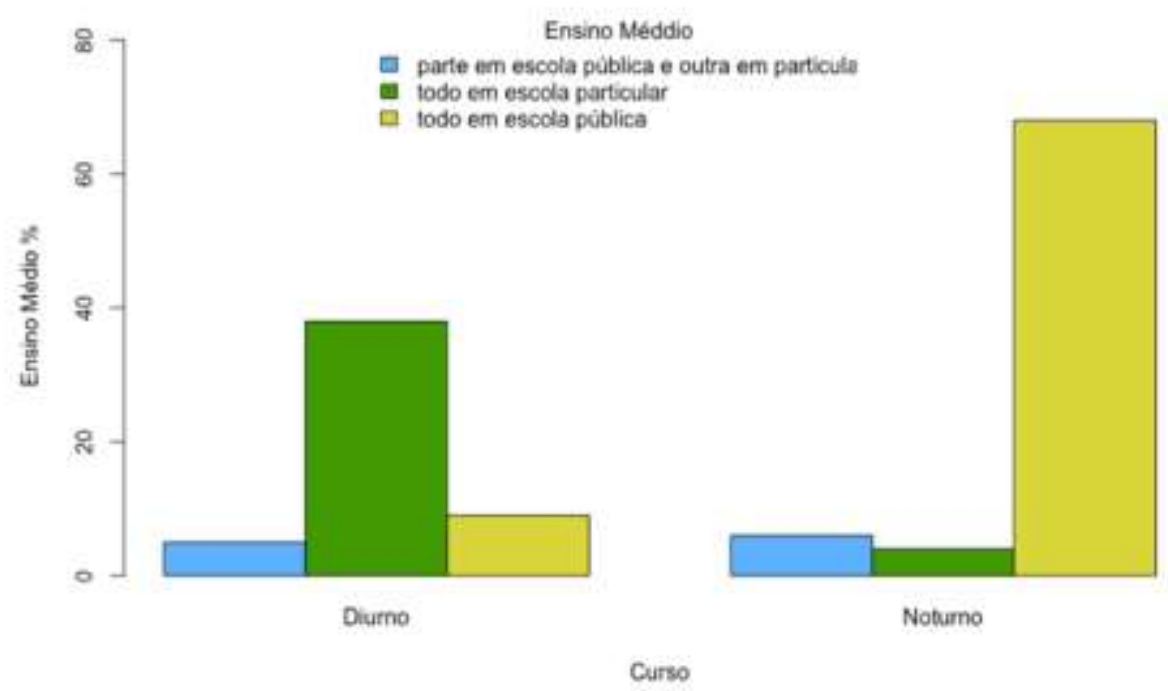

Fonte: Autores (2021)

Tabela 3: Fatores de estudo prévio dos discentes dos cursos de agronomia e zootecnia entrevistados no ano de 2019.

\begin{tabular}{|c|c|c|c|}
\hline \multicolumn{4}{|l|}{ Variável Analisada } \\
\hline & & Global (\%) & IC $(95 \%)$ \\
\hline \multirow{3}{*}{ Ensino médio } & todo em escola pública & 59,23 & $50,78 \%-67,68 \%$ \\
\hline & todo em escola particular & 32,31 & $24,27 \%-40,35 \%$ \\
\hline & $\begin{array}{l}\text { parte em escola pública e outra } \\
\text { particular }\end{array}$ & 8,46 & $3,68 \%-13,24 \%$ \\
\hline \multirow{6}{*}{ Tempo parado } & até 6 meses & 45,38 & $36,82 \%-53,94 \%$ \\
\hline & de 6 meses a 1 ano & 15,38 & $9,18 \%-21,58 \%$ \\
\hline & até 3 anos & 23,08 & $15,84 \%-30,32 \%$ \\
\hline & até 5 anos & 5,38 & $1,50 \%-09,26 \%$ \\
\hline & até 10 anos & 2,31 & $0,00 \%-4,89 \%$ \\
\hline & mais de 10 anos & 8,46 & $3,68 \%-13,24 \%$ \\
\hline \multirow{4}{*}{ Aprendizado química } & fraco & 35,38 & $27,16 \%-43,60 \%$ \\
\hline & mediano & 28,46 & $20,70 \%-36,22 \%$ \\
\hline & bom & 27,69 & $20,00 \%-35,38 \%$ \\
\hline & excelente & 8,46 & $3,68 \%-13,24 \%$ \\
\hline
\end{tabular}

Fonte: Autores (2021)

Em relação ao curso, diurno ou noturno, a situação final do aluno não obteve associação significativa. Em contrapartida, o teste Qui Quadrado $\left(\chi^{2}=12,804, \mathrm{df}=4, \mathrm{p}\right.$-value $\left.=0,01\right)$ mostra relação forte entre a situação final do aluno e o sexo. As mulheres, apesar de minoria, se destacam entre os "Aprovados".

Com base nos dados, é importante ressaltar quais variáveis são, ao nível de 5\% de significância, associadas à situação final do aluno. A Tabela 5 apresenta o p-valor do teste Qui Quadrado de cada relação. 
Tabela 4: Situação final dos discentes dos cursos de agronomia e zootecnia entrevistados no ano de 2019.

\begin{tabular}{llrr}
\hline Variável Analisada & & & \\
\hline & & Global (\%) & \multicolumn{1}{l}{ IC (95\%) } \\
\hline \multirow{4}{*}{ Situação final } & Aprovado & 58,46 & $49,99 \%-66,93 \%$ \\
& Reprovado & 27,69 & $20,00 \%-35,38 \%$ \\
& Abandono & 5,38 & $1,50 \%-09,26 \%$ \\
& Cancelou & 4,62 & $1,01 \%-08,23 \%$ \\
& Trancado & 3,85 & $0,54 \%-07,16 \%$ \\
\hline
\end{tabular}

Fonte: Autores (2021)

Tabela 5: Teste Qui Quadrado entre Situação Final dos discentes dos cursos de agronomia e zootecnia entrevistados no ano de 2019 e as outras variáveis consideradas na pesquisa.

\begin{tabular}{llr}
\hline Variável & $\boldsymbol{p}$-valor \\
\hline & Sexo & 0,01 \\
& Idade & 0,85 \\
& Cor & 0,03 \\
& Estado Civil & 0,09 \\
& Filho & 0,97 \\
& Renda & 0,02 \\
Situação final & Residência & 0,59 \\
& Trabalha & 0,55 \\
& Horas de Sono & 0,34 \\
& Formas de Estudo & 0,001 \\
& Ensino Médio & 0,22 \\
& Tempo Parado & 0,01 \\
& Aprendizado em Química & 0,98 \\
\hline
\end{tabular}

Fonte: Autores (2021)

As variáveis "Idade, Estado Civil, Filho, Residência, Trabalha, Horas de Sono, Ensino Médio, Aprendizado em Química” não são estatisticamente significantes para a situação final do aluno entrevistado.

Em contrapartida, ao mesmo nível de significância, as variáveis, "Sexo, Cor, Renda, Formas de Estudo, Tempo Parado", apresentam uma forte relação associativa com a situação final do aluno. Mulheres, da cor branca, a maioria com renda entre 1 e 6 salários mínimos, que estudam mais (diariamente ou semanalmente ou então dias antes da prova) e terminaram o ensino médio há menos de seis meses apresentaram melhores coeficientes de aproveitamento na disciplina de Química.

\section{Considerações Finais}

Mediante as conceptualizações realizadas, frente aos dados coletados e analisados, evidencia-se a prevalência geral de estudantes do sexo masculino nos cursos de Zootecnia e Agronomia matriculados na disciplina de química no ano de 2019. Em contrapartida, pode-se mostrar a relação associativa dos estudantes do sexo feminino com a situação final, como "Aprovado". O fator tempo longe da escola, ou seja, há quanto tempo o discente concluiu o ensino médio, mostrou-se relevante na 
aprovação na disciplina, independente se o ensino médio foi todo em escola pública, ou todo em escola particular, ou misto. Outro determinante relevante é o tempo que o aluno se dedica estudando para a disciplina, os que mais estudam consequentemente tiverem melhores resultados. Por fim, apesar das variáveis "Residência, Trabalha e Horas de Sono" não estarem estatisticamente relacionadas com a situação final do aluno, na Tabela 2, mostrou-se a relação forte entre elas e a forma de estudo. É natural afirmar que o fato de os alunos terem que viajar todos os dias, trabalharem o dia todo e terem poucas horas de estudo, naturalmente influência nas formas de estudo, dedicação e o aproveitamento frente à disciplina analisada.

Como sugestões para trabalhos futuros, após conhecer o perfil dos discentes, espera-se incluir no desenvolvimento estudantil, um acompanhamento pedagógico mais personalizado que permita identificar o uso de diferentes metodologias que sejam capazes de alcançar principalmente os alunos que apresentam a necessidade de viajar todos os dias, resultando em um maior aproveitamento frente ao curso.

\section{Agradecimentos}

Os autores agradecem à Instituição Faculdades Associadas de Uberaba (FAZU) por permitir a aplicação do questionário e a realização do estudo.

\section{Referências}

Araújo, E. A. T., Camargos, M. A., Camargos, M. C. S. \& Dias, A. T. (2013). Desempenho acadêmico de discentes do curso de Ciências Contábeis: uma análise dos seus fatores determinantes em uma IES privada. Ver. Contab. Vista \& Revista, 24, 60-83.

Artuzo, F. D., Jandrey, W. F., Drebes, L. M., Marchi, P. M., \& Silva, V. R. (2012). Perfil dos ingressantes do ensino superior do curso de agronomia da UFSM Campus Frederico Westphalen. Enciclopédia Biosfera, 8(15), 2528-2540.

Coelho, A. T., Lorenzini, L.M., Suza, E.Y., Rossini, S. \& Reimão, R. (2010). Qualidade de Sono, Depressão e Ansiedade em Uni versitários dos últimos semestres de cursos da área da saúde. Neurobiologia, 73.

Colossi, N., Consentino, A. \& Queiroz, E. G. (2001). Mudanças no contexto do ensino superior no Brasil: uma tendência ao ensino colaborativo. Rev. FAE, 4, 49-58.

Cunha, J. V. A., Cornachione-Jr., E. B., De-Luca, M. M. M. \& Ott, E. (2010). Modéstia de alunos de graduação em Ciências Contábeis sobre o desempenho acadêmico: uma análise pela ótica da teoria da autoeficácia. In: Congresso USP de Controladoria e Contabilidade, São Paulo - SP, Anais, FEA-USP, 10.

Ferreira, M. (2009). Determinantes do Rendimento Académico no Ensino Superior. Ver. Intern. D'Humanitats, 55-60.

Instituto Nacional de Estudos e Pesquisas Educacionais Anísio Teixeira (INEP) (2018). Censo da educação superior. http://portal.inep.gov.br/web/guest/censoda-educacao-superior.

Jahara, R. C., Corbo, A. R., \& Mello, J. A. V. B. (2016). Evolução do perfil socioeconômico de ingressantes de um curso de en genharia de produção após a adoção do ENEM como forma de ingresso. Revista Científica Interdisciplinar, 3(4), 28-44.

Koche, J. C. (2011). O fluxograma da pesquisa científica. In Fundamentos de metodologia científica. 122-136. Vozes.

Macedo, S. G., Verdinelli, M. A. \& Stuker, H. (2003). Modelo estatístico de análise na avaliação institucional: apresentando um recorte do desempenho docente. In: Coloquio Internacional sobre Gestión Universitaria em América do Sur, 3 Buenos Aires-ARG.

Marques, B. S., \& Silva, M. A. C. (2017). Trabalhadores-alunos: motivações e desafios que configuram um cenário de luta. Encontro Internacional de Gestão, Desenvolvimento e Inovação, Naviraí. https://doi.org/10.1017/CBO9781107415324.004.

Martins, B. V. \& Rocha-de-Oliveira, S. (2017). Qualificação Profissional, Mercado de Trabalho e Mobilidade Social: Cursos Superiores de Tecnologia. Sociedade, Contabilidade e Gestão, 12, 21-45.

Medeiros Filho, A., Rodrigues, Y., Lopes, J., \& Pontes Junior, J. (2019). Fatores associados ao desempenho discente no exame nacional de desempenho dos estudantes (ENADE): uma revisão integrativa. Revista Expressão Católica, 8 (1), 87-96. http://dx.doi.org/10.25190/rec.v8i1.2543

Oliveira, D. P., Ramos, M. R., \& Caglioni, E. (2020). Profile of the students enrolling in the Agronomic Engineering Course at a public university in the state of Tocantins, Brazil. Research, Society and Development, 9, 1-25.

Pereira A. S., Shitsuka D. M., Pereira F. J., \& Shitsuka R. (2018). Método qualitativo, quantitativo ou quali-quanti. In Metodologia da pesquisa científica. 6369. Santa Maria, RS: UFSM 
Research, Society and Development, v. 10, n. 2, e43310212747, 2021

(CC BY 4.0) | ISSN 2525-3409 | DOI: http://dx.doi.org/10.33448/rsd-v10i2.12747

Rocha, A. L. P., Leles, C. R., \& Queiroz, M. G. (2018). Fatores associados ao desempenho acadêmico de estudantes de Nutrição no Enade. Revista Brasileira de Estudos Pedagógicos, 99(251), 74-94. https://doi.org/10.24109/2176-6681.rbep.99i251.3162

Souza, K. R., \& Kerbauy, M. T. M. (2017). Abordagem quanti-qualitativa: superação da dicotomia quantitativa-qualitativa na pesquisa em educação. Educação e Filosofia. 31 (61), 21 - 44. Uberlândia.

Tomazetti, E. M., \& Schlickmann, V. (2016). Escola, ensino médio e juventude: a massificação de um sistema e a busca de um sentido. Educ. Pesquis, 42, 331-342. 